\title{
"P-R" differences in intact cockroaches as a function of testing interval
}

\author{
J. DISTERHOFT, ${ }^{1}$ J. NURNBERGER, and W. C. CORNING, \\ Animal Behavior Laboratories, Department of Psychology, \\ Fordham University, Bronx, N. Y. 10458
}

One group of intact cockroaches was trained to keep a leg flexed in order to avoid a shock ( $P$ group) while a yoked control group $(R)$ received shock independent of leg position. During retesting sessions where both $P$ and $R$ were trained, $P$ received less shock than $R$ on same-day and $24 h$ retests but after $48 h, R$ was avoiding better than $P$.

The use of simpler systems in researching learning and memory mechanisms has recently received considerable impetus from the successes of several molluscan and arthropod preparations (Bullock \& Quarton, 1966; Kandel \& Spencer, 1968). In particular, the leg position conditioning obtained by Horridge (1962) in the headless cockroach has been a convincing demonstration that mammalian learning paradigms are possible in such preparations. Basically the procedure was to position the cockroach over a dish of saline, attach a thin wire to the upper part of the leg, and arrange a circuit so that the leg received a shock whenever it extended into the saline ("P" animal). A control (" $R$ " animal) was hooked in series so that its leg received a shock whenever the P animal did. Although the P animals would receive less and less shock as training progressed, the critical test of whether learning had occurred was to assess the P-R differences during a retest session given on the same day where both $\mathbf{P}$ and $\mathbf{R}$ were subjected to training treatments. During this session it was found that $P$ received less shock than $R$ although $R$ would eventually learn. Others have determined that an isolated ganglion with its associated leg could still acquire the avoidance response (Eisenstein \& Cohen, 1965).

Our interest in the development of this preparation was stimulated by the automated nature of the experimental set-up and the relative lack of equivocation in judging responses-the leg was out of the saline or it was completing the circuit and receiving the shock. The difficulty with the headless roach is that the life of the animal is foreshortened; this makes impossible any study concerned with the behavior of the animal over extended periods of time. To develop a more viable preparation we trained intact cockroaches that had been immobilized in such a way that there was minimal damage, and measured $P-R$ differences at specific intervals after the original training.

\section{METHOD}

The Ss were 46 male and female cockroaches, Periplaneta americana, captured in a refuse area of the Bronx Zoo. All Ss were housed together in light-free containers until used for experimentation, at which time they were placed in individual containers. Water and food were available at all times.

To prepare an animal for experimentation it was first immobilized by placing it in a refrigerator at $-2 \mathrm{deg} C$ for $10-15$ min. The cooled.roach was placed on its back on a $5 \mathrm{~cm}$ square block of wood and tied with dental floss placed between the prothoracic and mesothoracic legs. Rubber bands were used to secure to the block the antennae and all legs with the exception of the left mesothoracic leg. An 80 micron silver wire was tied to the upper tibia or lower femur of the free leg of both P and R animals; an additional wire was tied to the tarsus of $R$ Ss. Training and testing was carried out in a dark cubicle and effort made to keep extraneous stimuli at a minimum. During initial training the $\mathbf{P}$ and $\mathrm{R}$ Ss were arranged in series according to the methods described by Horridge (1962): Whenever P extended its leg and closed the circuit, $\mathbf{R}$ would also receive a shock. This yoked control procedure ensured that $R$ experienced the same amount of shock as $P$, but unlike $P$, the shock was independent of position. The shock levels were adjusted for each P-R pair so that reliable leg responses were observed. Square-wave pulses were delivered at 3-4
$\mathrm{Hz}$ and a record of shocks received was obtained with a Varian G22 Dual Channel Pen Recorder.

Three groups were studied: Group SD (seven P-R pairs) was trained and retested on the same day with 15 min elapsing between training and testing; Group ID (eight P-R pairs) was retested $24 \mathrm{~h}$ after training; and Group IID (eight P-R pairs) was retested $48 \mathrm{~h}$ after training.

\section{RESULTS}

Using P-R differences during the retest sessions where both $P$ and $R$ were trained, it was found that the $P$ Ss received less shock than $R$ in Groups SD and ID (see Fig. 1). For the SD pairs, the P-R differences were statistically significant (sign test, Siegel, 1956) at the $0-10 \mathrm{~min}(\mathrm{p}<.02), 10-20 \mathrm{~min}(\mathrm{p}<.02)$, and at the $30-40 \mathrm{~min}$ interval $(p<.05)$. The R Ss of Group SD did not learn during retesting. In the ID group, the P-R differences were significant at the $0-10(\mathrm{p}<.025), 10-20(\mathrm{p}<.005)$, and at the $20-30 \mathrm{~min}$ interval $(\mathrm{p}<.01)$. At $30-40 \mathrm{~min}$ there was little difference between ID $P$ and $R$ animals as the $R$ animals began to avoid shock in the later stages of the retesting period.

In Group IID there was a reversal in the average P-R differences, i.e., $\mathbf{R}$ received less shock than $\mathbf{P}$ during the retesting. While this was not statistically significant it does represent a change from the results obtained with the other two groups. Examination of the R group's performance during retesting provides an explanation for the P-R reversal in IID (Fig. 2). Whereas the R groups of SD and ID received considerable shock at the beginning of training, in IID the R Ss showed rapid avoidance of the shock. From the data of Fig. 2 it can also be seen that as the interval between the yoked control treatment and the retesting session is increased, the performance of $R$ improves; $R$ Ss trained on the same day do not learn, those trained after $24 \mathrm{~h}$ show some avoidance near the end of training, and in IID they demonstrate immediate avoidance.

When the original training performance and retest performance of the P Ss in the groups are compared, it is found that there was significant savings during the retesting $(p<.003)$.

Generally, the behavior exhibited in this training situation was highly variable from animal to animal. The use of both males and females did not contribute to this variability as we found no differences between sexes. The immobilization procedures were found to be particularly successful with only occasional damage inflicted to a S. Once freed from the block the probability of survival was enhanced.

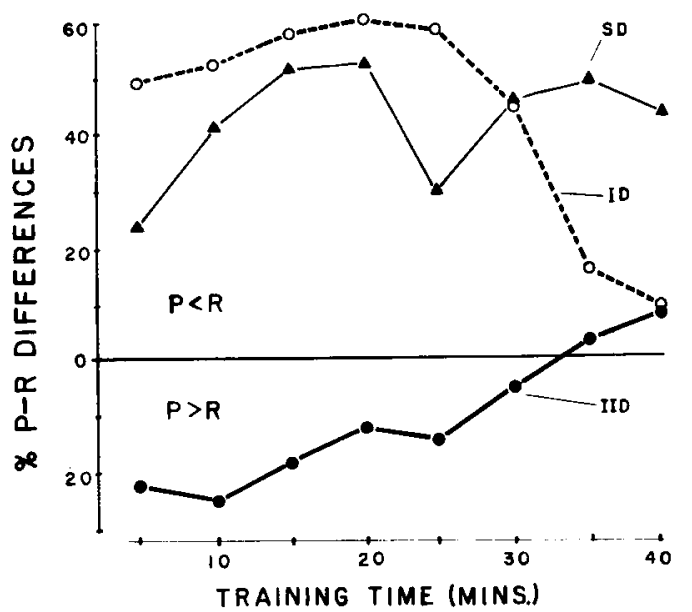

Fig. 1. P-R differences in groups tested at different intervals after training. "SD": animals tested 15 min after training. "ID": animals tested $24 \mathrm{~h}$ after training. "IID": animals tested $48 \mathrm{~h}$ after training. The difference scores were calculated from the per cent time leg was in saline. 


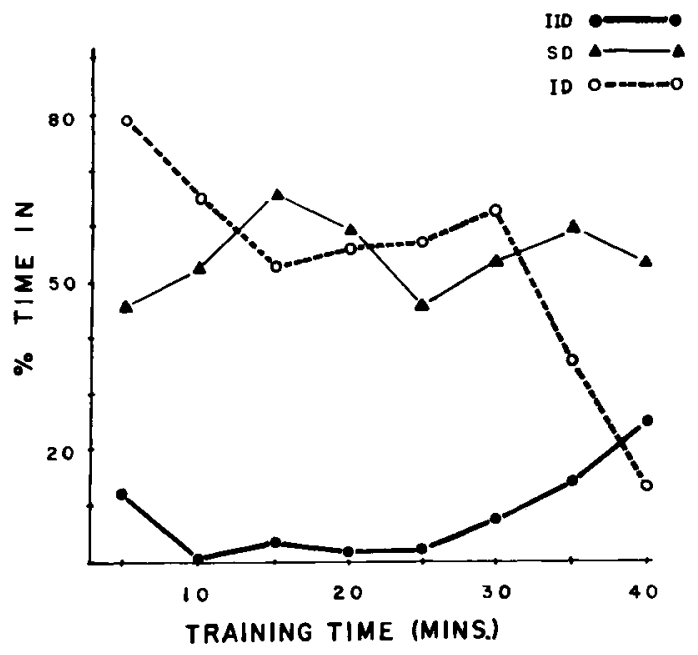

Fig. 2. Per cent time in saline of $\mathbf{R}$ groups during training (retest session). "SD," "ID," and "IID" are the same groups defined in Fig. 1.

\section{DISCUSSION}

From these data it is apparent that the intact cockroach can acquire the avoidance response demonstrated by others in decapitated and isolated ganglia preparations (Eisenstein \& Cohen, 1965; Horridge, 1962). However, using P-R differences as an indication of learning, it is also clear that while the $P$ groups perform better than $R$ during tests given immediately after training and $24 \mathrm{~h}$ later, the P-R differences not only disappear but show a small reversal at $48 \mathrm{~h}$. This change in the difference scores is mainly due to the improved performance of the control animals. The yoked control treatment would seem to have produced a change that facilitates acquisition but this effect does not manifest itself until $48 \mathrm{~h}$ after the control experience. It has previously been suggested in studies using an isolated ganglion preparation that $R$ Ss learn a number of associations between leg position and shock (Eisenstein \& Cohen, 1965). This results in a poorer performance by $R$ animals when they are trained as they first must extinguish past associations. If this interpretation is correct then $R$ can accomplish this sorting out process much more quickly if a 48 $h$ interval is allowed to elapse. Why $R$ should perform a little better than $P$ cannot be determined from the present study.

As for using this particular training task over extended durations, our findings suggest that factors influencing the behavior of the control group need to be delineated first in the intact cockroach. It may be that the $R$ group is not the best control to use or that certain procedural variations may stabilize P-R differences-for example, Eisenstein (1967) has suggested the use of a single preparation where one leg is $P$ and another is $R$ in order to reduce variability.

\section{REFERENCES}

BULLOCK, T. H., \& QUARTON, G. C. Simple systems for the study of learning mechanisms. Neurosciences Research Bulletin, 1966, 4, No. 2.

EISENSTEIN, E. M. The use of invertebrate systems for studies on the bases of learning and memory. In G. C. Quarton, T. Melnechuk, and F. O. Schmitt (Eds), The neurosciences New York: Rockefeller Univ. Press, 1967. Pp. 653-665.

EISENSTEIN, E. M., \& COHEN, M. J. Learning in an isolated prothoracic insect ganglion. Animal Behavior, 1965, 13, 104-108.

HORRIDGE, G. A. Learning of leg position by the ventral nerve cord in headless insects. Proceeding of the Royal Society of London. Series B, $1962,157,33-52$.

KANDEL, E. R., \& SPENCER, W. A. Cellular neurophysiological approaches to learning. Physiological Reviews, 1968, 48, 65-134.

SIEGEL, S. Nonparametric statistics for the behavioral sciences. New York: McGraw-Hill, 1956.

NOTE

1. NDEA Graduate Fellow, Fordham University. 